In Focus

\title{
The Hanged Rhizome on the Tree: Arborescence and Multiplicity in Disco Elysium
}




\begin{abstract}
This paper looks at Disco Elysium as a model for a better understanding of Gilles Deleuze and Felix Guattari's concept of the rhizome when applied to video games. It analyses the use and implementation of the many forms of expressing multiplicity that are present in Disco Elysium and that are manifested through the configuration of the avatar, the use of the player's choice, and representations of space and time in the game. Ultimately, this paper also serves as a coalescence of existing Game Studies scholarship on rhizomic relations, multiplicities and affect to create a common ground for future conversations on these topics.
\end{abstract}

My first contact with Disco Elysium [D.E] could be best described as the feeling of distress after waking up with the most acute and painful symptoms of a hangover; everything that could go wrong went wrong and the world seemed hell bent on punishing me for my choices. After creating a detective with a relative high intellect and psyche, I failed to escape the money-grubbing manager of the motel where my detective was staying, pirouetting into a pair of pinball cabinets [and possibly an old lady on a wheelchair] and dying. After re-loading, I failed at punching Cuno, a drug-addict twelve-year-old kid in the face, and fell to the floor. My character passed out after spending too much time inspecting some files. I failed at talking some Communist sense into a book shop owner who was employing her underage daughter. I stressed out after thinking that I would never collect on time the money I owed the manager of the Whirling-in-Rags. And, moments later, my detective lost his will to live during a radio conversation and died. When I tried to load a save file, I discovered that the autosave function had not worked since the very beginning of the game (meaning all my

efforts at failing had been for nothing). Kim, the detective's partner, observed everything and probably wiped his glasses afterwards. It took me a while to try the game again, even if I eventually loved the experience of repeated failure. The multiple nature of the things I both managed and failed to do during the abundant conversations in the game resonated with existing research on failure (Ruberg 2017; Juul 2013) and caught my academic interest.

At the beginning of the game, D.E asks players to create their own detective by assigning points to four different attributes: intellect, psyche, physique, and motorics. As the number of points players can allocate is limited, the game invites players to imagine the type of detective they want to be - intelligent, empathic, strong or agile - and focus on the attribute(s) that would best define their character. Each attribute governs in turn six different skills, for a total of twenty-four, that range from easyto-understand ones such as hand-eye coordination to less obvious ones such as inland empire. This system is not very different from the ones used by many RPGs where the actions characters can perform as well as the chances at succeeding or failing at them are all determined by 
attributes such as intelligence, wisdom or charisma and by skills like lock-picking, intimidation or stealth. In D.E, skills are not only abilities that allow players to perform specific actions, such as punching Cuno or inventing a name for oneself. The detective's competence with skills can be further altered by what he wears or the substances he consumes. Whenever players choose to perform an action that requires a skill, they are shown a percentage with their chances of success. Failure and success are determined by rolling a pair of dice, with actions the detective is skilful at requiring a lower minimum result. No matter how skilful the detective is at something, chances of success will never reach either 0 or $100 \%$, as getting a total of two or twelve in the dice rolls results respectively in automatic failure or success.

Skills are also checked automatically during conversations and inner monologues to decide whether the detective manages to perceive certain intentions or feelings, think up explanations on the go, or conceive certain ideas as conversations unfold. These perceptions and thoughts are represented during conversations as voices [most named after a skill] that players and the detective can read and hear. These voices can either add some extra details and dialogue options to conversations, sometimes leading nowhere in particular - such as using inland empire to imagine a conversation between the detective and a corpse - or at other times can convince and stir the detective in certain directions, making new missions available by inseminating his mind with new thoughts. Thoughts are not just temporary ideas. Once discovered, players can place them into a grid called the thought cabinet to internalise them. Once internalised, thoughts serve as identity-defining traits that further determine the character by reinforcing or negatively impacting some skills, opening up certain dialogue options made available by the identity-changing nature of internalising a thought, or allowing him to perform specific actions. In D.E, the process of coming to accept an idea or belief is an identity- changing procedure that directly affects whether - and how well - some actions can be carried out.

In addition to attributes, skills, and thoughts, the detective's responses and actions affect his ideological and moral stances. In this sense, acting upon certain ideas and tenets convinces the detective of what the game understands these beliefs to represent, triggering certain reactions from other characters and sometimes expanding dialogue options. As a result, the detective can be the product of multiple combinations of attributes, skills, clothes, and internalised thoughts and beliefs. Even the detective's name can be negotiated. Harry Du Bois, Raphaël Ambrosius Costeau, and Tequila Sunrise are the three I discovered. Because of so many variables, I will keep using the detective to refer to the main character in D.E for the rest of this paper.

Previously, scholars (Stang 2019; Sanfold et al. 2009; Mukherjee 2015; Murray 1997; Cremin 2012; Carr 2003) have used Gilles Deleuze and Felix Guattari's notion (1980) of the rhizome to describe and define several different elements of video games. All of them understand the rhizome as a multiplicity of planes and an amalgamation of converging possibilities and affects that resist attempts at isolating and identifying unequivocal unities, as do I. The rhizome has been applied to different ways of implementing space, to ways of understanding machinic interactions between games and players, as well as paratexts, such as fan discussions, wikis, or usergenerated mods. This paper will use the rhizome to think about D.E and its forms of understanding and presenting choice, identities, storytelling, and space. My aim is to discuss the ways in which a game such as $D$.E, with multiplicity at the core of its design, both is, and is not, an example of the rhizome in video games. My next section will study choice and multiplicity.

\section{HANGED CHOICE: ARBORESCENCE, RHIZOMES, AND A CORPSE.}

Choosing is central when playing D.E. 
Players choose the kind of detective they want and what he will say, do, wear, and believe. Understanding choice is also central to Game Studies.

Miguel Sicart's work on choice is probably one of the most influential in the field. Sicart is particularly interested in the connection between choice and ethical thinking in games. This author differentiates between choices that engage players at an ethical or moral level and choices that are part of a mere reward/punishment system. While the latter type of choice entails little to no moral activation, as choosing gets reduced to selecting the most rewarding - or least punishing - option, the former allows games to be seen as "complex interrelations between a system, the metaphors used to communicate with players, and the way that players interpret these metaphors as cultural and embodied beings who are socially situated in the activity of play" (Sicart 2013: 39). For Sicart, the morality inserted into video games though choices that activate players' ethical values connects the game world with the players' own reality and values. This connection works at least in two directions. The game reproduces certain moral values through the choices it invites players to make, and the players exert some limited form of moral agency when choosing. This vision is similar to Mia Consalvo, Thorsten Busch, and Carolyn Jong's (2016) ideas regarding player's choice and agency. These authors see games as potential caterers of individual agency. An agency that is, however, modified and restricted by what games push players to do or how rewards and punishments are handled in response to players' choices.

Engaging choices as Sicart sees them go beyond simplistic distinctions between "good" or "bad". This is because clear-cut distinctions prevent most choices from becoming ethical dilemmas. When posed with "Good/Bad" dichotomic choices, Amanda Lange (2015) explains, the majority of players choose a game's good path, at least when they are completing the game for the first time. This tendency changes during subsequent playthroughs, with players be- ing more willing to experience more evil options once they have completed the game. Daniel M. Shafer (2012) claims that, when players do choose to be evil or to perform morally questionable actions, they implement some cognitive strategies to absolve themselves and justify their actions. While this author does not find any significant differences in enjoyment connected to particular moral choices, he also points out that players tend to choose "good" options when they are morally activated, or engaged, by the game. Lange's and Shafer's ideas might be connected by a common thread since players' sense of discovery when completing the game for the first time makes them more engaged with their actions, influencing the type of choices they make.

J. Yellowlees Douglas and Andrew Hargadon (2004) perceive a continued evolution in the complexity of choice in video games. For these authors, with the passing of time, video games become more complex in the kinds of interactions they offer. Their vision, however, is not shared by Richard Schechner's (2004) response to Douglas and Hargadon's text. Schechner claims that choice in video games is similar to the act of choosing from a menu in a restaurant; regardless of the number of elements people can choose from, their choices will always be limited to the items listed. A long and varied menu that gets bigger with the passing of time may make costumers feel as if their personal tastes were increasingly catered to, but the result would be the same since customers end up choosing from a pre-selected number of choices in an expanding menu that attempts to make larger groups of people more satisfied. More choices lead to a more ready consumption of the goods on offer. Choice can indeed be seen as a powerful ideological tool that promotes some particular identitarian options, roles and behaviours deviously, while ignoring others.

When options are easily identifiable as simple either/or dilemmas, the chances of having players choose guided by the rewards that each choice offers become higher. 
Conceptually, a dichotomy is everything a rhizome is not. A dichotomy is the simplest form of an arborescent categorization: two branches leading in two clearly defined directions, in this case, good and evil. As choices become more complex, the number of branches increases and this dichotomy becomes a tree of options. Yet, regardless of the number of branches, player's choice always depends on the designers' primordial selection. While the increase in the number and complexity of choices indeed represents an expansion in the identities being portrayed in video games, this expanding multiplicity is not rhizomic in nature. To use Deleuze and Guattari's terms, we could say that greater amounts of choice in video games deterritorialise discourses and identities not yet included in video games only to reterritorialise them.

For Souvik Mukherjee (2015), video games are assemblages that result from the union of players and the game and story engines during gameplay. These game-assemblages are in turn connected to other assemblages (economic, commercial, bureaucratic, or juridical), each influencing the others. Although for this author seeing videogames as rhizomes is a stretch, Mukherjee also argues that video games do have certain rhizomic qualities as they deterritorialise, or extract and reterritorialise/ reincorporate different lines belonging to other assemblages. I would argue that the very act of extracting and reincorporating a line can be perceived, however, as an act of isolating and identifying those very lines; an act that potentially unravels these rhizomic qualities. An example can be extracted from the relationship between games and ideology. When games expand the romance options, they offer players more diverse choices; they incorporate specific lines that had been ignored before and had never been part of the game-assemblage. These additions not only reproduce existing forms of understanding desire or affect, making them more concrete and categorisable, but also actualize these desires and affect in particular ways. As I explained in an earlier piece, (Belmonte Avila 2013), games that include the option of same-sex romance not only add the choice of another affective expression, but they also understand and categorize the agents of these expressions - both within and outside the game - by making them follow pre-designed actions. Expanded choices result in more inclusive games that address more potential identities. However, having a designer choose the players' own choices is, in itself, a limiting and identity-defining move. This is because designing choices involves flattening or streamlining identities, simplifying them.

If we go back to a metaphor used above, the creation of a menu and the act of choosing from it both shape and concretise identity. With more choices built into them, video games open up possibilities that expand from dichotomies to paths shaped as complex branching structures. However, video games are coded to contain a fixed number of choices. As such, they connect with a specific number of identities, and they cannot be fully rhizomic. If we pay attention to choice in video games, could I say (at least for now) that choice is always arborescent and therefore, never rhizomic? Possibly. Let's analyse this idea in relation to D.E.

It would be difficult to describe choices in D.E as being either/or dichotomies since almost any action players perform is one out of many options. Examples of this multiplicity include the attribute points allocated at the beginning of the game that impact a rather large number of skills; the potential combinations of these skills and the way they open up and close down certain actions and dialogue options; the way players can further configure their detectives through clothes and internalized thoughts, or the way and the order in which objectives and missions become available and can be completed.

During the first days of the investigation, players will probably spend a significant amount of time working on the body hanging from the tree. Advancing the investigation by managing to get close to the body without puking, by trying different ways of taking down the body without 
dying, by performing the autopsy on the corpse to then, maybe, find a fridge for it, are all central to completing the compulsory objectives in the game. Even if this number of actions to be completed seems quite sequential, players are free to speak to whomever they want and explore the map, except for areas that become available later in the week. While doing so, the detective can be exposed [and expose himself through the hive of voices in his head] to thoughts, objectives and missions that take the player temporarily away from the corpse on the tree. Some of these side missions allow him to meet, gain favour with, or antagonise characters that later become relevant in the main missions. In this sense, side missions are not always diversions or truly secondary; sometimes players might spend (like I did) several minutes reloading their games trying to pass a very difficult skill check only to discover that succeeding and coming up with Tequila Sunrise as an alternative name for the detective does not achieve much beyond fleeting approval.

The detective's ability to perceive and think about what he sees and hears also plays a critical role in the number of missions that become available to players. During one of my early playthroughs, my detective passed an automatic dice roll to realize that Lawrence Garte, the manager of the Whirling-in-Rags, had feelings for Sylvie, a former employee who had recently quit her job. Garte thought he was responsible for Sylvie's resignation and I (thinking that by helping them my detective would somehow reduce the amount of money he owed Garte) decided to make my detective intervene. In subsequent playthroughs, however, my detective did not notice Garte's worries and I never had the chance to volunteer, as the option to help Garte was never there. The game chose for me before I even knew what potential options were opening up and closing down in the background. In a sense, my initial choice of attributes and the invisible result of automatic dice rolls chose for me, altering the experience I had with the game, even if I knew that something I had found earlier was now missing. And, when I realized this, I automatically compared D.E with one of my most prominent memories of playing Baldur's Gate II: Shadows of Amn (BioWare 2000) as a teenager. Relatively early into the game my party was exploring the sewers of Athkatla when we ran into a group of mind flayers. Being around level 9, my party got massacred repeatedly. I did not have any resurrection spells. Minsc, my not-so-very wise or intelligent front-line ranger, got his brain pulled out of his skull every time, and the damage my characters dealt in proportion to the damage they sustained was far from ideal. It was too early for me to explore that area of the game populated by those enemies, but I knew that they would still be there once I chose to fight them later. The option of helping Garte in D.E automatically disappeared once my detective failed to perceive the manager's feelings. There was no way for me to return to him to offer my help unlike the 17-year-old me who got back to the sewer weeks later and exerted revenge on the brain-suckers.

A system that chooses for the player without them noticing could be defined as limiting. Yet, it is the player's initial choice what determines, together with the randomness of the dice rolls and the additional opportunities of further configuring the detective as the game progresses, which options become available to players and what parts remain invisible. In a sense, it is easy to describe D.E as not being rhizomic: even if the choices are ample and the experience of playing fluctuates depending on the myriad of factors described above, the game operates with a closed number of variables. Even if these variables are far from limiting players' choices to good and evil dichotomies, they are still part of a closed number of possibilities. The choices are set in an arborescent, branching pattern even if the tree of possibilities is complex and flexible. No matter how the detective is configured at the beginning of the game or what side-missions players decide to complete, the detective and Kim will repeatedly have to return to the corpse hanging on the tree. The corpse and the 
tree are at the centre of all the arborescent choices during the investigation, directing players towards specific goals. And, even when the players' choice is their own, it will never fully be so. The dice add the possibility of failing in every action while certain successes have outcomes that players may not be able to predict - such as my detective dying once because the chair he sat on was ... uncomfortable.

My use of the terms arborescent and rhizomic has been a bit circuitous. If my claim is that no game can be rhizomic because they are closed texts that contain a limited number of choices, then, what is the point of discussing rhizomes when studying video games? Should we hang the rhizome on the arborescent tree to let it rot next to the corpse? That is, should we ignore the rhizomic elements games have because of the arborescent traits they also possess? We should not. The corpse on the tree, as a central knot from where lines branch out in an arborescent way, condenses some of the reasons why the game is not rhizomic in some regards. Yet, this does not mean that the game cannot be used as an example of rhizomic representation. Let us explore how this can be.

\section{UNEARTHING THE RHIZOME IN DISCO ELYSIUM.}

One of the ways rhizomes have been discussed in video games is in relation to space. Since I have been referring to the centrality of the corpse and the tree in D.E, space is a good place to start this section. Diane Carr (2003) distinguishes two main types of space in video games: maze-like labyrinths involving conditional progression towards an exit and rhizomic environments where exploration and wandering are encouraged or, at least, made possible. Silent Hill (Konami 1999), with its corridors and puzzles, is as an example of the first kind and Planescape: Torment [P:T] (Black Isle Studios 1999) of the second. For Carr, P:T allows players to excavate both the history of the gameworld and the story of the game through the exploration of space. Upon release, Disco Elysium was compared to P:T by both fans and reviewers (Schreier 2019; Kershaw 2019), with the team behind D.E openly showing their appreciation for the older game on social media (@discoelysium 2019). Even if both games are different in some areas, with D.E solving all types of confrontation through dialogue options and $P: T$ having a more traditional approach to combat, both titles indeed focus on exploration.

Ciara Cremin (2012) sees in the exploration of space a way of establishing a rhizomic relationship between two wills -or artists, as she calls them: that of the designer-artist and of the player-artist. For Cremin, game designers create two main types of spaces. The first of these types is what Cremin defines as striated spaces and are not far from Carr's labyrinths. Striated spaces have a very defined structure that limits movement in a prescribed form. Smooth spaces, a close equivalent to Carr's rhizomic environments, allow the expression of diverse desiring intensities that manifest themselves through exploration and discovery. For Cremin, Super Mario Galaxy [SMG] (Nintendo 2007) exemplifies smooth spatiality. It combines the affects of the designers with a freedom of movement particular to this game. Is SMG a perfect example of a rhizome? Of course not. Exploration is still restricted by boundaries, progression is still conditioned to the collection of specific items, and players can be punished for doing wrong things or playing badly. Yet, Cremin wants us to focus on the ways the game uses gravity, fluid 3D movement, and liminality to multiple responses produced by players. As such, even if it may not be a rhizome, a game such as SMG is a metaphor and a perfectly good excuse to think about some of the ways in which games can partially function as rhizomes.

Disco Elysium could work in a similar way, both for its use of space and for the many and variable dialogues it contains. If I were to apply Cremin's distinction of striated and smooth spaces, it would be easy to differentiate between striated and smooth choices, with striated choices being clear cut options with definite, mostly pre- 
dictable, outcomes and smooth choices offering more complex connections and less obvious results.

Something Carr and Cremin do not mention that, in my view, also affects how space is experienced by players is time. Silent Hill, Carr's example for maze-like labyrinths, combines limited resources, an oppressive atmosphere, and scary foes to create a sense of urgency that, ironically, demands a thorough exploration of space to access the two best endings in the game. By contrast, neither P:T nor SMG impose any urgency or time limits on players. Compared to 2D entries in the Mario series, where movement is far more limited, levels in 3D Mario games do not have a time limit. This does not mean that 2D Mario games do not reward exploration. Super Mario World (Nintendo 1990), for instance, requires players to carefully explore levels if they want to unlock the special colour Yoshis. However, by eliminating time restrictions, the 3D Mario games give players the time to develop multiple responses. Rhizomic possibilities and multiplicities are not only spatial but also temporal.

In this respect, D.E plays with time and freedom of exploration in a peculiar way. One of the first objectives players apparently need to complete is to pay Garte the money the detective owes him before the end of the first day. Should they completely fail to collect the money, their detective will have nowhere to sleep, and the game will end. I have written completely and apparently in italics because even if they do not collect any money through bribes or other means, Kim offers to help the detective in time to solve the problem. Players just need to pay attention to Kim. This solution, however, is not something players will know about when prompted with the need to collect money, unless, of course, they are using a guide, or they are not playing the game for the first time. They will only be aware of the clock ticking away and the amount of money they need to amass, a small fortune given how inexpensive many things are in the game. The ticking, digital clock, however, does not really have any impact on spatial exploration. When the detective wanders around the map, the clock simply does not advance; it only does when he talks to other characters or performs certain actions, such as reading through reports and files. Hence, while D.E does allow for the exploration of space without time pressure - even if some areas of the map do not become available until specific days of the week it does impress a sense of time efficiency on the conversations and actions. This time-oriented efficiency takes away from the freedom players have when exploring options and side-missions. This becomes especially true given the uncertain outcomes of many actions, such as dying after choosing to sit on an uncomfortable chair, and dialogue choices. In a game where the possibility of failure is constant no matter how skilled the detective, the meaning of success is often very uncertain. This uncertainty amounts sometimes to wasted time which, in turn, limits the players' actions. My point, however, is not that time is used in D.E to direct the player's actions towards time-efficient goals and actions, even if it sometimes does. Instead, I want to think about how failure and unexpectedness connected to time can make a game more rhizomic.

\section{IT'S DISCO (RHIZOME) TIME!}

Souvik Mukherjee (2017) invites the reader to think about memory and failure. Mukherjee claims that the players' memory of their successes and failures in a game determines their identities when playing. The experience of failing and having to repeat an action or section is not completely erased upon loading a previous save file and trying again. In this sense, repeated failures at overcoming an obstacle are not fully erased by the one success that allows players to continue, nor are they fully remembered separately. Instead, failures erased upon loading a save file exist together as an amalgamation of the whole past. Mukherjee, borrowing from Henri Bergson's Matter and Memory, Gilles Deleuze's Bergsonism and Cinema 1, and Alia Al-Saji's "The Memory of Another Past: Bergson, Deleuze 
and a New Theory of Time," explains that memories affectively influence the present actions as well as the player's mind and body in the form of a "multiplicity of various contractions of the past" (2017:61). Similarly, Cremin (2016), also borrowing from Bergson, invites us to think about the effect of memory and perception on video games. Cremin explains that, for Bergson, consciousness is the capacity to perceive the present by using the accumulation of past experiences and to convert predictions (shaped by our past experiences) into present actions. This idea has a clear application to the player's skills in that, the more experience as a player somebody has accumulated, the better they should be able to respond to what games throw at them. However, these predictions based on past experiences also apply to games at other levels, such as the ways players consume and participate in a game's story, or the forms in which games can bring back to the surface very personal experiences that are not necessarily ludic, such as associating one's state of mind at any specific point in time to the playing of particular title.

In a game so determined by multiplicities as D.E., failure and loading previous save states are a continuous possibility, both because players' actions result in unwanted and unexpected outcomes and because of actual failures during skill checks. Additionally, the branching possibilities originating from the different ways in which the detective can be built also invite players to start the game from the beginning [as I did after my initial chain of failures described in the introduction] or to complete the game more than once to try different detectives. In all these cases, choices made and then unmade upon reloading, secondary missions completed only for the player to load a state when these missions did not yet exist, thoughts discarded after they were assimilated, and many deaths that are undone upon reloading, never truly cease to be. Instead, they form layers of experience that coalesce as a rhizome to further multiply the already based-on-multiplicity experience of playing D.E; and this is a rhizome not based separately on choice, representations and use of space, or on interactions between designers and players, but on all these elements together and amalgamated in time. Thinking about the rhizome not only as a spatial concept based on planes, plateaus, or layers but also as a time-based construct might be essential to unearthing the rhizome (or maybe a rhizome or a form of rhizomic expression) in games. When choice is restricted, space bound, and potential outcomes limited, time multiplies what is and what was into a more rhizomic experience.

Scholars such as Kathy Sanfold, Liz Merkel, and Leanna Madill (2009) and Sarah Stang (2019) invite us to think about video games as rhizomes by paying attention to what players can do once they are no longer playing, including interpreting certain aspects of games, interacting with other players and game designers in forums or social media, or creating spaces for interpreting, remediating, or modifying games. Since reactions, interpretations and communities generated from games happen around these games they are also irremediably linked to a time that takes place after playing. This vision of the rhizome is tied to a future that exists in relation to the moment of play - once players (will) close the game and do something related to it that is not just playing. In this sense, the temporal rhizome I described in the previous paragraphs, understood primarily as an amalgamation of different instances of the past and the present, is also oriented towards the future. Just as different past failures coalesce in the present, the rhizome that they form is left open for future rhizomic offshoots to be added.

This paper is, in itself, a temporal rhizome around D.E that makes past, present, and futures coalesce. It is based on my past experiences of playing the game, thinking about it, doing research in order to write about it, and then sending it to an editorial team for review. As I have been writing this piece, I have been asking myself questions such as: Will the editor like my paper? Will the other authors use D.E to refer to Disco 
Elysium? Will the other papers in this collection be significantly different/similar to mine considering we are all writing about the same game? Or what will readers think of this text and how are their experiences of the game compared to mine? All of these questions are different layers, past, present and future, placed together around the game. This collection of papers is, in itself, an unpredictable rhizome, originating from a myriad of sources and waiting to establish what are, at least right now, unforeseeable and multi-directional connections. It connects past experiences with present instances of playing, thinking, and writing that now belong in the past, present instances of reading that soon will cease to be [that is, you, reader, with only 19 words left to finish this paper] and future potentialities that my personal inland empire is simply unable to predict.

\section{ACKNOWLEDGEMENT}

This research has been funded by project number PGC2018-095393-BI00.

\section{WORKS CITED}

Belmonte Avila, Juan 2013. 'Identity and through Free Choice? The Frontier of Gender and Sexuality in Computer Games'. -Benjamin Bigl, Sebastian Stoppe (eds.), Playing with Virtuality: Theories and Methods of Computer Game Studies. Frankfurt: Peter Lang, 285-298.

Black Isle Studios 1999. Planescape: Torment. Los Angeles: Interplay Entertainment.

BioWare 2000. Baldur's Gate II: Shadows of Amn. Irvine: Black Isle Studios.

Carr, Diane 2003. 'Play Dead: Genre and Affect in Silent Hill and Planescape: Torment'. - Game Studies 3, 1. Consalvo, Mia; Busch, Thorsten; Jong, Carolyn 2016. 'Playing a Better Me: How Players Rehearse Their Ethos via Moral Choices'. - Games and Culture 14, 3, 1-20. Cremin, Ciara 2012. 'The Formal Qualities of the Video Game: An Exploration of Super Mario Galaxy with Gilles Deleuze.' - Games and Culture 7, 1, 72-86.

----------- (2016). Exploring Videogames with Deleuze and Guattari. Towards an Affective Theory of Form.

London and New York: Routledge.

Deleuze, Gilles; Guattari, Felix 2009 [1980]. A Thousand Plateaus. Capitalism and Schizophrenia. Minneapolis: University of Minnesota Press.

Douglas, Yellowlees; Hargadon, Andrew 2004.

'The Pleasures of Immersion and Interaction: Schemas, Scripts, and the Fifth Business'. - Noah Wardrip-Fruin, Pat Harrigan (eds.), First Person. New Media as Story, Performance, and Game. Cambridge: MIT Press, 192-206.

Juul, Jesper 2013. The Art of Failure: An Essay on the Pain of Playing Video Games. Cambridge: MIT Press. Kershaw, Rob 2019. 'Disco Elysium is This Generation's Planescape Torment'. -Jump Dash Roll, https://www. jumpdashroll.com/article/disco-elysium-is-this-generations-planescape-torment (27 February 2021) Konami Computer Entertainment Tokyo 1999. Silent Hill. Tokyo: Konami.

Lange, Amanda 2015. 'Beyond Binary Choices: How Players Engage with Morality'. Presentation at Game Developers Conference 2015. https://www.gdcvault. $\mathrm{com} /$ play/1021833/Beyond-Binary-Choices-HowPlayers (7 March 2021)

Mukherjee, Souvik 2017. 'Re-membering and dismembering: memory and the (re) creation of identities in videogames'. - Sessões do Imaginário 22, 38, 53-63. ------- 2015. Games and Storytelling. Reading Games and Playing Books. London: Palgrave Macmillan. Murray, Janet 1997. Hamlet on the Holodeck. The Future of Narrative in Cyberspace. New York: The Free Press. Nintendo EAD Tokyo 2007. Super Mario Galaxy. Kyoto: Nintendo.

Nintendo EAD 1990. Super Mario World. Kyoto: Nintendo.

Ruberg, Bonnie 2017. 'Playing to Lose: The Queer Art of Failing at Video Games'. - Jennifer Malkowski, TreaAndrea M. Russworm (eds.), Gaming Representation: Race, Gender, and Sexuality in Video Games. Bloomington: Indiana University Press, 197-211. Sanfold, Kathy; Merkel, Liz; Madill, Leanna 2009. 'There's no Fixed Course: Rhizomatic Learning Communities in Adolescent Videogaming'. - LOADING.. The Journal of the Canadian Game Studies Association $5,8,50-70$.

Schechner, Richard 2004. Response to Yellowness and Hargadon's 'The Pleasures of Immersion and Interaction: Schemas, Scripts, and the Fifth Business'. - Noah Wardrip-Fruin, Pat Harrigan (eds.), First Person. New Media as Story, Performance, and Game. Cambridge: MIT Press, 192-206.

Shafer, Daniel 2012. 'Moral Choice in Video Games: 
An Exploratory Study.' - Media Psychology Review 5, 1. Sicart, Miguel 2013. Beyond Choices: The Design of Ethical Gameplay. Cambridge: MIT Press.

Schreier, Jason 2019. 'Disco Elysium: The Kotaku Review'. -Kotaku. https://kotaku.com/disco-elysiumthe-kotaku-review-1839723176 (27 February 2021) Stang, Sarah 2019. 'This Action Will Have Consequences: Interactivity and Player Agency'. - Game Studies, $19,1$.

ZA/UM Studio 2019. Disco Elysium. London: ZA/UM

Studio.

@discoelysium, Official Disco Elysium Twitter

Account 2019.https://twitter.com/discoelysium/ status/1205225193653731328 (10 March 2021). 